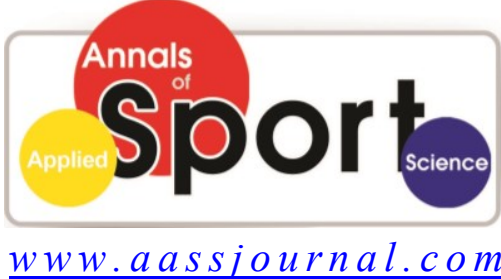

ISS N (Online): $2322-4479$

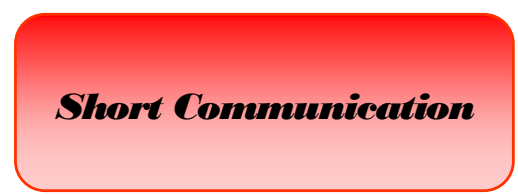

Received: 26/04/2014 Accepted: 14/07/2014

\title{
The Effect of Pairwise Video Feedback on the Learning of Fine Eye-Hand Coordination Skill
}

\section{${ }^{1}$ Majid Arab*, ${ }^{1}$ Seyed Mehdi Dastfal, ${ }^{1}$ Ehsan Zareian}

1. Department of Motor Learning, Faculty of Physical Education and Sport Science, Allameh Tabataba'i University, Tehran, Iran.

\begin{abstract}
The present paper aimed to study the effect of pairwise video check feedback (including the observation of external pattern of skill performance and performing the skill simultaneously) on the learning on acquisition and learning of eye-hand coordination skill. Computer skill of eye-hand coordination skill was the tool used in this study. 24 subjects were randomly selected and equally divided into two groups of experimental and control. Each of the groups performed 3 exercise sessions of 5 attempts with a 24-hour interval between sessions. In each exercise attempt, the experimental group conducted a combination of pairwise video feedback and practical performance of the skill and the control group only performed the practical exercises. Acquisition tests were done at the end of training sessions and retention tests were performed after intervals of 24 hours, 48 hours, and one week after the last session of acquisition. Performing the task in lesser time was the criteria for assessment of individuals. The results showed a significant improvement in the performance of task from the pretest to the final stage of acquisition. Also, over time ( 24 hours, 48 hours, and after the last training session) in retention test, a stability in performance was seen. Finally, it was found that pairwise video feedback method positively affect the acquisition of skill and retention stability of individuals in eye-hand coordination skill.
\end{abstract}

Key Words: Outer Pattern, Self-Model, Observational Learning, Visual Feedback.

Corresponding Author:

Majid Arab

E-mail: majidarab1369@gmail.com 


\section{INTRODUCTION}

Performance is an observable behavior, while learning cannot be seen directly and should be inferred from individual performance in retention test (1). Retention and transfer tests provide the signs that would have preserved the habits acquired in the absence of training or information on the method in which the previous exercise affects the performance of a new task (2).

Pairwise video feedback is one of the ways to learn sport skills (1). In this method, coaches show the video feedback of the leaner's movements with the visual model of correct movement. Actually, this method is based on the observation both the external pattern of skill performance and the performance of the skill by the leaner himself/herself (observational learning). One of the advantages of this method is the provision of a form of correct movements when the learner is performing a skill. When learners try to reduce the inconsistency between the target movement (desired) and their own movements (real), this feedback may increase their awareness of the optimum (2). Most knowledge about the benefits of skill display in learning belongs to Bandura's research on modeling and social learning (1). Skill display allows the leaners to visually relate the oral description of the skill to information obtained from the valid tokens of the task for a successful performance (3). On the other hand, when someone sees a model, the pattern of skill will be learned with a focus on the spatial and temporal characteristics of that skill. In order to develop the movement pattern, the observer perceives and uses the fixed (quintessential) aspects of movement coordination pattern (4). Arising from observational learning, neuromuscular effects theory confirms the effect of pairwise video feedback on learning of motion skills. According to this theory, neuromuscular effects resulting from observational learning are similar to practical exercise and the effects of motion learning, which includes sensory and motor systems, would be achieved through both practical exercise and observational learning method (1).
One of the most important evidence of research that examines the impact of observation is the studies on the perception of movement through observation. Research on perception of human movement refers to two phenomena that help us understand the observational learning; first, individuals can accurately and quickly diagnose different patterns of movement without seeing the whole body or its all moving organs, and second, individuals do not perceive the characteristics of a movement like movement speed of the organ in order to recognize a movement pattern, but they understand the unchanging relationship between the two constituent parts of that movement as the most important piece of information. So, it can be assumed that these constant relationships in coordinated movements provide important information about observational learning (1). As Magill (2011) pointed out, the effect of display on learning of a skill is dependent on the features of that skill. The most beneficial impact of display occurs when learning a skill requires acquisition of a new pattern of coordination (1). In terms of the external pattern used in observation, it should be stated that the external pattern can be either skillful or unskillful that are used, respectively, to train skillful individuals and beginners (1).

As mentioned before, pairwise video feedback is based on observation of performance of oneself and the external pattern. There are some studies in this area with different models of study method (5-14) that aren't enough.

According to the research, it has been known that practical exercise is not necessary for learning motion skills. However, in some special circumstances such as learning new skills that are dangerous (like piloting) or when there is injuries and physical disabilities, practical exercises are not possible to be done. Hence, application of alternative methods to practical exercise can be effective for learning a skill. Pairwise video feedback is one of these alternatives which is based on observational learning and is conducted through observation

Arab, M., Dastfal, S. M., Zareian, E. (2014). Ann Appl Sport Sci, 2(3): 07-12. 
of external pattern when the learner himself/herself is performing a skill. The effect of displaying the video of performance of oneself and the external pattern on learning of motion skills has been separately studied in many researches, while the combination of these two methods needs to be studied further. Hence, the objective of the present study is to find that whether pairwise video feedback is effective in learning or not.

\section{MATERIALS AND METHODS}

Participants. In the present study, 24 students of Allameh Tabataba'i University in the academic year 2013-2014 were selected as sample. Inclusion criteria included righthandedness, enjoying a full visual health, full consent to participate in research, and being the age group of $25 \pm 2.4$.

Pretest-posttest with a control group was the main method of this study which consisted of pretest, acquisition test, and retention tests after 24 hours, 48 hours, and one week after the last session of acquisition. According to the scores gained in pretest, the sample was equally divided into two groups of experimental (12 subjects) and control (12 subjects).

Tools. Eye-hand coordination task in this study was performed using a computer game (4-wheel madness). The validity of this tool was confirmed by experts and its reliability coefficient was measured 0.67 by test-retest method. In the task, individuals were supposed to look at the route of the task and pass the car on the track in the shortest possible time considering the obstacles. The task was controlled using four arrow buttons on a portable computer keyboard (Laptop ASUS $\mathrm{x} 44$ model). The time of passing the car on the track by each subject was recorded as the measurement criterion. Screen recorder was another tool used to prepare an initial patterned educational video clip and to record the performance of individuals to be displayed for them in the next attempts as a pattern. Scoring criterion was the decrease in time of passing the car on the track (in second) by the subjects.

Procedure. Firstly, a patterned video clip in which the way of performing the task in 4- wheel madness was presented by the examiner was displayed for the subjects. Each of the subjects exercised the task for 10 minutes to become familiar with and then the pretest was performed. According to the results of the pretest, the subjects were equally divided into two groups of experimental and control. In the skill acquisition stage, both groups exercised for 3 session ( 5 attempts) with an interval of 24 hours (one day). Experimental group in each attempt first watched the video of correct external pattern and the video of their own previous performance and then conducted the practical exercise in computer task for 5 minutes. It is important to point out that the experimental group watched the video of their own pretest performance before the first attempt of the first session of acquisition. Each attempt of individuals was recorded by screen recorder and displayed for them before the next attempt as a pattern. The control group exercised the same sessions and attempts but pairwise video feedback was not used for them. At the end of each session of acquisition, the subjects fully passed the task route once and their time was recorded to show their progress. Finally, the retention test was performed 24 hours, 48 hours, and one week after the last session of acquisition in which all subjects did the task and their final score was recorded.

Statistical Analysis. Kolmogorov-Smirnov test was used to verify the normality of data. Then, the Leven Test was used to assess homogeneity of variances between the two groups. Finally, progress of subjects was examined by repeated measures-ANOVA. The analysis was performed by Statistical Package for Social Sciences (SPSS) and statistical significance level was set at the 0.05 .

\section{RESULTS}

According to the results, the Mauchly's test was significant $(\mathrm{W}=0.12, \mathrm{p}=0.01)$ and so the assumption of sphericity is not confirmed. Hence, Greenhouse- Geisser correction was used. There is a significant interaction effect of TIME and GROUP $(\mathrm{F}=11.588, \mathrm{p}=0.001)$; so that There is a significant difference experimental and control groups in terms of 
progress, indicating the effect of pairwise video feedback on learning of eye-hand coordination skill. The progress of experimental and control groups during the various stages of acquisition and retention is shown in Figure 1.

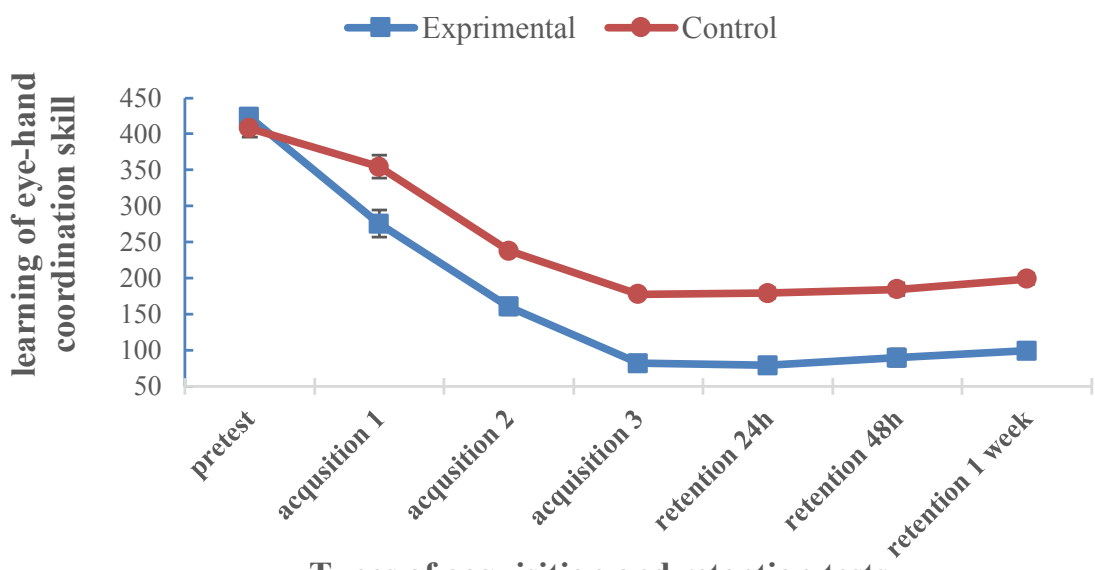

Types of acquisition and retention tests

Figure 1: Performance of subjects in acquisition and retention tests. Slope was greater for the experimental group which suggests the effect of independent variable (pairwise video feedback) on learning of eye-hand coordination skill in this group. Also, given that scoring criterion was the decrease in time of passing the car on the track, both groups showed progress in acquisition stages (from stage 1 to stage 4 ) during exercise. The results of retention test 24 hours, 48 hours, and one week after the last session showed that the performance of subjects did not change significantly over time.

\section{DISCUSSION and CONCLUSION}

The main objective of the present paper was to study the effect of pairwise video feedback on acquisition and retention of eye-hand coordination skill. The results of statistical analysis showed that pairwise video feedback method has a significant impact on acquisition and retention of eye-hand coordination skill. The findings correspond with Bandura's social learning theory and confirm it. According to this theory, observational learning is an activity containing information processing. In this type of learning, the leaner acquires a cognitive display of a skill and uses it for the production and regulation of his/her movements. It is also used as the criterion of correct movement for realizing errors in performing a skill (15). The results of the present study are also consistent with the findings of Bernardi et al. (2013) who showed that sensory-physical functions change during observational learning and become similar to those of practical exercise. This result supports the theory of similarity between the neuromuscular effects of observational learning and practical exercise. According to this theory, the effects of motion learning, which includes sensory and motor systems, would be achieved through both practical exercise and observational learning method (10). The results are also consistent with the findings of Fagard, Esseily, and Nadel (2006) who showed that showing how to obtain an object that is not directly accessible is more effective than practical exercise in 15month children and this effect becomes significant in 18-month children (12). In a research conducted by Miletić, Jeličić, and Oreb (2007), the impact of observation of visual model on the performance of individuals in dancing was studied and it was shown that display of skill would provide useful information for the beginners in dancing. This develops the memory representation of motion skill and leads to the learning of the skill (14). Shayan et al. (2012) and Ehsani et al. (2009) found the similar results as the present study about the positive impact of observation of oneself performance on learning of motion skills $(5,7)$. Suzande pour et al. (2009) and Pirmoradian, Movahedi, and Bahram (2013) 
obtained significant results on the positive impact of observation of external pattern on learning a skill that are consistent with the findings of the present study $(8,9)$. It is noteworthy to say that no inconsistent result with the present study was found on the effect of observational method on learning of motion skills.

In summary, the present study confirmed the positive and significant effect of pairwise video feedback method, which is based on observation of a combination of oneself performance and external pattern. Previous studies have also confirmed such an effect. Bandura's social learning theory and theory of neuromuscular effects are of important reasons of such effectiveness (1). Bandura's social learning theory states that observational learning is a process which leads to individual recognition of the skills and production of movement. Skill display allows the leaners to visually relate the oral description of the skill to information obtained from the valid tokens of the task for a successful performance (4). On the other hand, when someone sees a model, the pattern of skill will be learned with a focus on the spatial and temporal characteristics of that skill. The observer exclusively perceives and uses the fixed (quintessential) aspects of movement coordination pattern. As mentioned before, the theory of neuromuscular effects resulting from observational learning is another theory that confirms the impact of pairwise video feedback on learning of motion skills. According to this theory, neuromuscular effects resulting from observational learning are similar to those of practical exercise and the effects of motion learning, which includes sensory and motor systems, would be achieved through both practical exercise and observational learning method. The results of the present study showed that pairwise video feedback has a positive and significant impact on acquisition and retention of eye-hand coordination skill and it can be used for skill training and rehabilitation of injured individuals.

\section{REFFRENCES}

1. Magill RA. Motor Learning and Control: Concepts and Applications. 9th ed: McGraw-Hill; 2011.

2. Schmidt RA, Wrisberg CA. Motor Learning and Performance: A Situation-based Learning Approach: Human Kinetics; 2008.

3. Weiss MR, Ebbeck V, Rose DJ. "Show and tell" in the gymnasium revisited: developmental differences in modeling and verbal rehearsal effects on motor skill learning and performance. Research quarterly for exercise and sport. 1992;63(3):292-301.

4. Zetou E, Tzetzis G, Vernadakis N, Kioumourtzoglou E. Modeling in learning two volleyball skills. Percept Mot Skills. 2002;94(3 Pt 2):1131-42.

5. Shayan A, Homeniyan D, AbediniParizi H, Fazel Kalkhoran J. The Interactional Effect of Modeling (Skilled and Self-Model) and Feedback on Performance and Learning of Dart Throwing Skill. Journal of Development and Motor Learning. 2012;4(10):123-42[Article in Farsi].

6. Ghavami A, Hosseini F, Mohammadzadeh H, Maleki B, Borhani H. The Effect of Observing Animated Model and Static Images and Combined Model on Motor Learning of Handstand Balance Skill. Journal of Development and Motor Learning. 2012;4(10):143-56[Article in Farsi].

7. Ehsani S, Arab ameri E, Farokhi A, Zeydabadi R. The Effect of Self-Controlled and Instructor-Controlled Feedbacks on Acquisition, Retention and Transfer of a Motor Skill Using Videotape Feedback. Journal of Development and Motor Learning. 2009;1(2):87-102[Article in Farsi].

8. Suzande pour R, Movahedi A, Mazaheri L, Sharifi G. The Comparison of the Effect of Two Methods of SelfModelling and Video Demonstration of an Expert on the Acquisition and Retention of Volleyball Serve Skill. Journal of Development and Motor Learning. 2009;1(1):61-77[Article in Farsi].

9. Pirmoradian M, Movahedi A, Bahram A. The comparison effects of video expert modeling and video self-modeling on the learning of basketball free throw in the children with mental retardation. Motor Behavior. 2013;4(11):133-46[Article in Farsi].

10. Bernardi NF, Darainy M, Bricolo E, Ostry DJ. Observing motor learning produces somatosensory change. Journal of neurophysiology. 2013;110(8):1804-10.

11. Mulder T. Motor imagery and action observation: cognitive tools for rehabilitation. Journal of neural transmission (Vienna, Austria : 1996). 2007;114(10):1265-78.

12. Fagard J, Esseily R, Nadel J. Learning through practice versus learning by observation in infants. 2006.

13. Vinter A, Perruchet P. Implicit motor learning through observational training in adults and children. Mem Cogn. 2002;30(2):256-61.

14. Miletić Đ, Jeličić M, Oreb G. The effects of a visual model and knowledge of performance on dance skills. Kinesiologia Slovenica. 2007;13(1):31-40.

15. Carroll WR, Bandura A. Role of timing of visual monitoring and motor rehearsal in observational learning of action patterns. Journal of motor behavior. 1985;17(3):269-81.

Arab, M., Dastfal, S. M., Zareian, E. (2014). Ann Appl Sport Sci, 2(3): 07-12. 


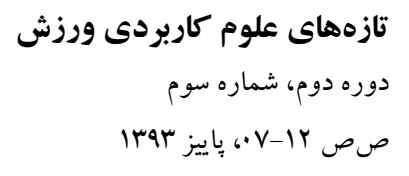

مقاله كوتاه

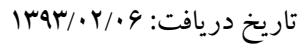

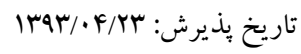

\title{
اثر بازخورد ويدئويى دوقطعهاى بر يادَيرى مهارت هماهنَى ظريف جُشم و دست
}

\author{
' مجيد عرب*، 'سيد مهدى دستفال، ׳احسان زارعيان
}

ا. كارشناس ارشد رفتار حركتى، دانشكده تربيتبدنى و علوم ورزشى، دانشخاه علامه طباطبايیى، تهران، ايران.

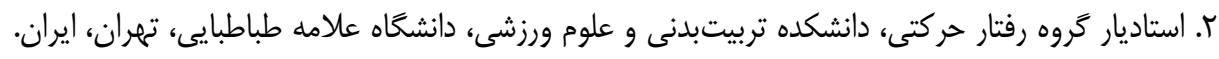

جُكيده

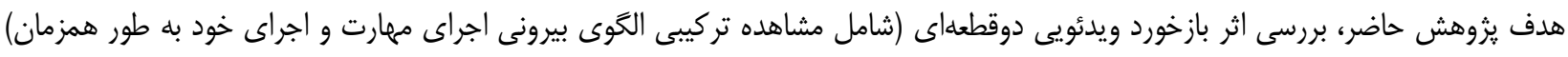

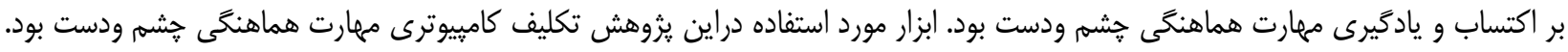

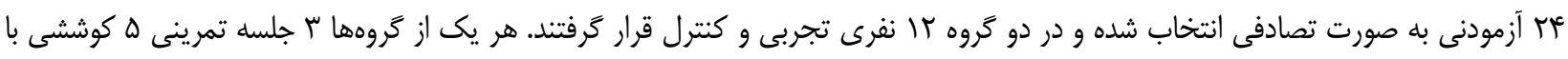

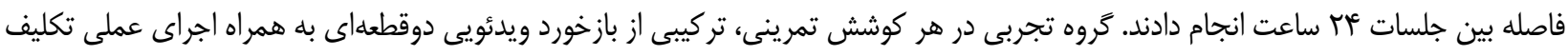

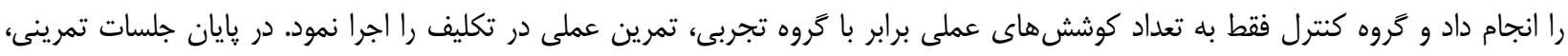

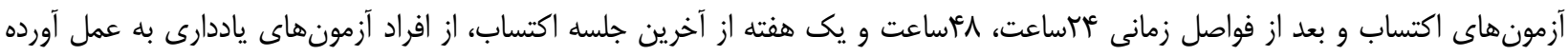

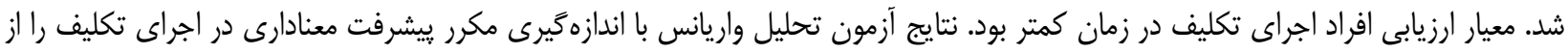

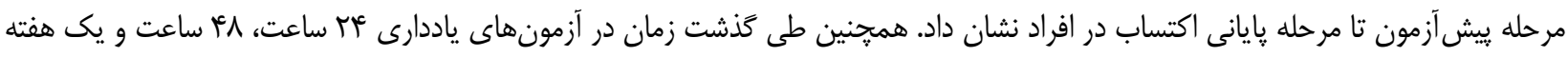

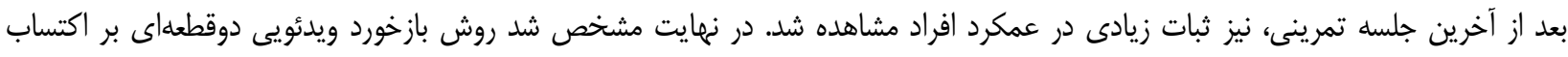

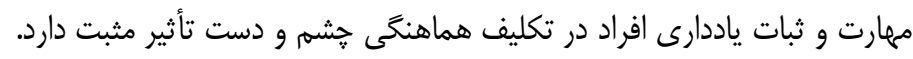

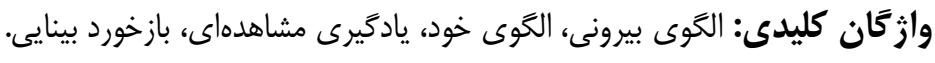

مجيد 